\title{
Journal of Dermatological Research
}

\section{Rough Pigmented Skin Around the upper Gluteal Cleft -the Condition Called Senile Gluteal Dermatosis, Hyperkeratotic Lichenified Skin Lesion of Gluteal Region, Ano-sacral Cutaneous Amyloidosis and Gluteal Skin Roughness-}

\author{
Masanori Ban
}

Masanori Ban, Ban skin clinic, Private practice, Hashima, Japan. Department of dermatology, Gifu university, Gifu, Japan

Conflict-of-interest statement: The author(s) declare(s) that there is no conflict of interest regarding the publication of this paper.

Open-Access: This article is an open-access article which was selected by an in-house editor and fully peer-reviewed by external reviewers. It is distributed in accordance with the Creative Commons Attribution Non Commercial (CC BY-NC 4.0) license, which permits others to distribute, remix, adapt, build upon this work noncommercially, and license their derivative works on different terms, provided the original work is properly cited and the use is noncommercial. See: http: //creativecommons.org/licenses/by-nc/4.0/

Correspondence to: Ban Hifuka, Masakicho Magari 1050-1, Hashima City, 501-6227, Japan.

Email: banhifuka@major.ocn.ne.jp

Telephone: +81-58-391-0056

Received: November 2, 2017

Revised: November 15, 2017

Accepted: November 17, 2017

Published online: December 26, 2017

\begin{abstract}
Rough pigmented skin is often seen around the upper gluteal cleft in the elderly. It is considered to be induced by friction, pressure and long hours sitting. Some cases revealing amyloid deposits may be accompanied by other cutaneous amyloidosis. Bedsores and fungal infection can occur as complications. This condition should be known widely among people taking care of the elderly.
\end{abstract}

Key words: Senile gluteal dermatosis; Hyperkeratotic lichenified skin lesion of gluteal region; Ano-sacral cutaneous amyloidosis; Gluteal skin roughness; Friction

(C) 2017 The Author(s). Published by ACT Publishing Group Ltd. All rights reserved.
Ban M. Rough Pigmented Skin Around the upper Gluteal Cleft the Condition Called Senile Gluteal Dermatosis, Hyperkeratotic Lichenified Skin Lesion of Gluteal Region, Ano-sacral Cutaneous Amyloidosis and Gluteal Skin Roughness-. Journal of Dermatological Research 2017; 2(4): 113-115 Available from: URL: http://www.ghrnet.org/index.php/jdr/article/view/2188

\section{EDITORIAL}

Elderly persons often get rough pigmented skin around the upper gluteal cleft. Hyperkeratotic parallel ridges and scale are seen in most lesions. Hypertrophy, papules, erythema and ulcers are done in some (Figure 1). Histology mostly reveals hyperkeratosis, acanthosis and follicular plugging (Figure 2). Friction, pressure and long hours sitting are considered to be triggers ${ }^{[1]}$. The general term for this condition seem to be unified to "senile gluteal dermatosis", which was proposed by Boss \& Koning in $1992^{[2]}$. Recently Liu et al..$^{[1,3]}$ and Moon et $a l^{[4]}$ examined the large number of cases and reported them using this term. They described that this condition was first reported in Japan as "hyperkeratotic lichenified skin lesions of gluteal region" ${ }^{[5]}$. The author here summarizes the discussions about it in Japan.

There was the first debate in a Japanese dermatological meeting in 1978. Yamamoto \& Mukai presented this condition as the result of mechanical stimulation in the elderly, and discussed with Mori who insisted that some cases belonged to a special type of cutaneous amyloidosis ${ }^{[5]}$. In 1979 Yanagihara \& Mori et al proposed the term "ano-sacral cutaneous amyloidosis" in another meeting, and discussed with Yamamoto again ${ }^{[6]}$. After those the debates continued on journals. In 1981 Yanagihara published a paper "ano-sacral cutaneous amyloidosis" ${ }^{\text {"[] }}$. He reported nine cases revealing amyloid deposits characteristically around follicles, and insisted it as a new type of cutaneous amyloidosis. The cases presented by Yamamoto \& Mukai were considered to be the same as ano-sacral cutaneous amyloidosis in his paper. In 1985 Yamamoto \& Mukai examined 14 cases by Dylon and Thyoflavin $\mathrm{T}$ stains, which react to amyloid ${ }^{[8]}$. Two cases showed no amyloid deposits, 10 did slightly, and two did abundant amyloid masses. Normal gluteal skins of three elder persons were also stained. Two of them revealed a small amount of amyloid. They concluded that amyloid did not mainly cause this condition and 


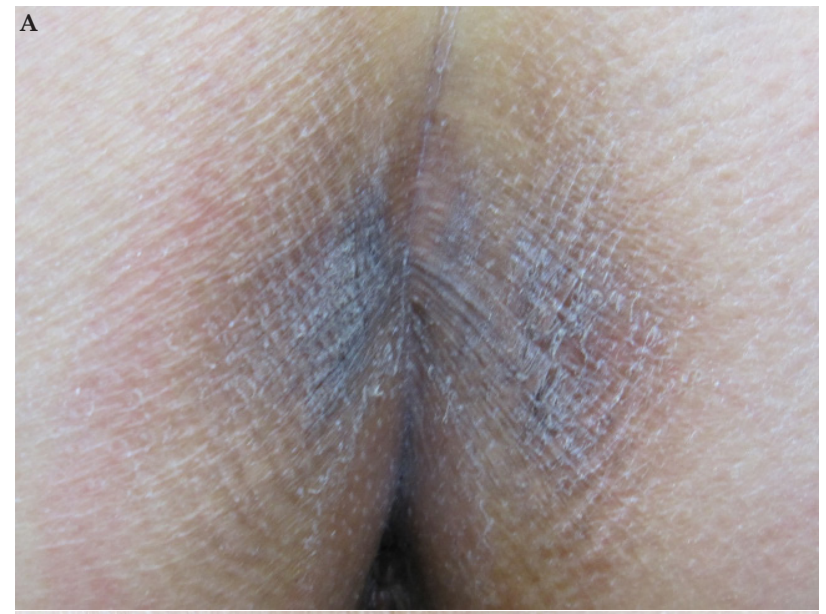

B

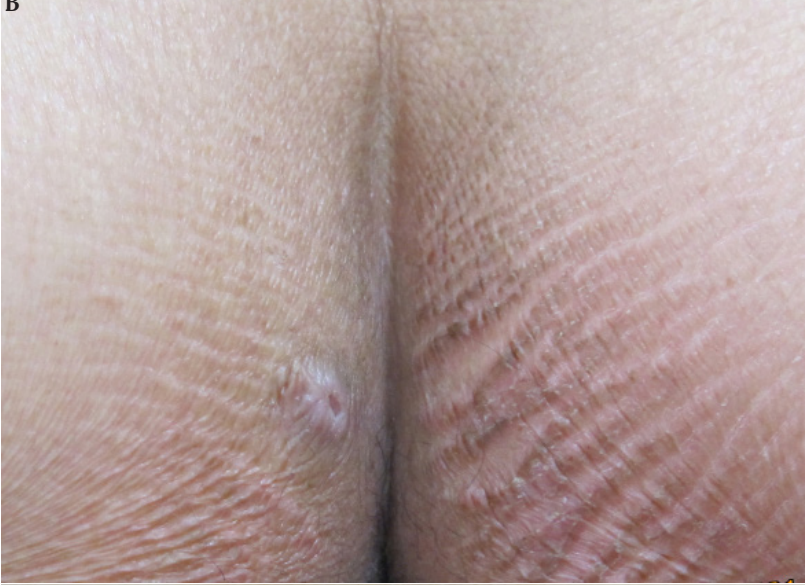

C

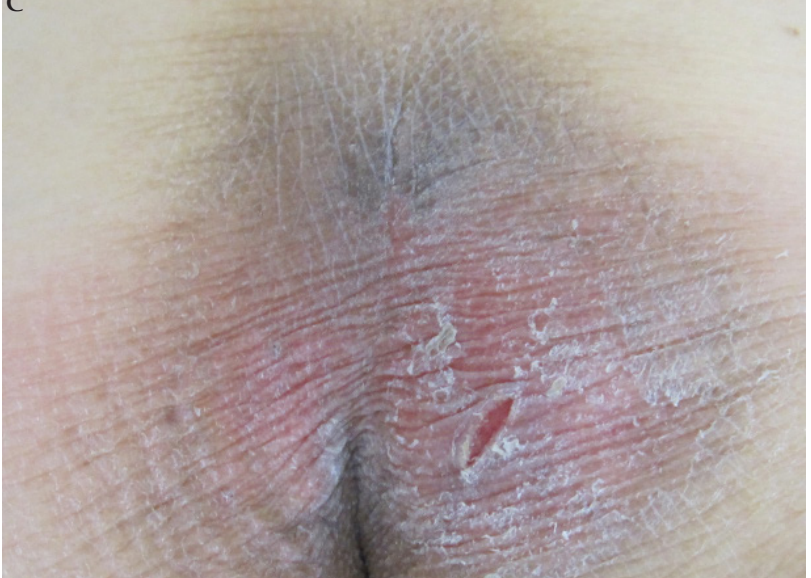

Figure 1 (A) A typical lesion revealing roughness and pigmentation. (B) A lesion with a papule. (C) A lesion with erythema and a small ulcer.

proposed the term "hyperkeratotic lichenified skin lesion of gluteal region". In 1986 Mukai \& Yamamoto et al wrote another paper to accept ano-sacral cutaneous amyloidosis as an entity different from hyperkeratotic lichenified skin lesion of gluteal region ${ }^{[9]}$. They reported five cases which revealed amyloidosis not only in gluteal regions but also in other cutaneous parts. Wakashin detected amyloid deposits in three cases out of eight in $1998^{[10]}$. Only a case showed them around the follicles. His autopsy experiences concluded that amyloid fibers were often seen in many organs of elderly persons as a kind of aging phenomenon. In 2000 Kojima proposed the third term "gluteal skin roughness"[11]. He described that this condition might arise in the aged carrier of hyperkeratotic diseases such as

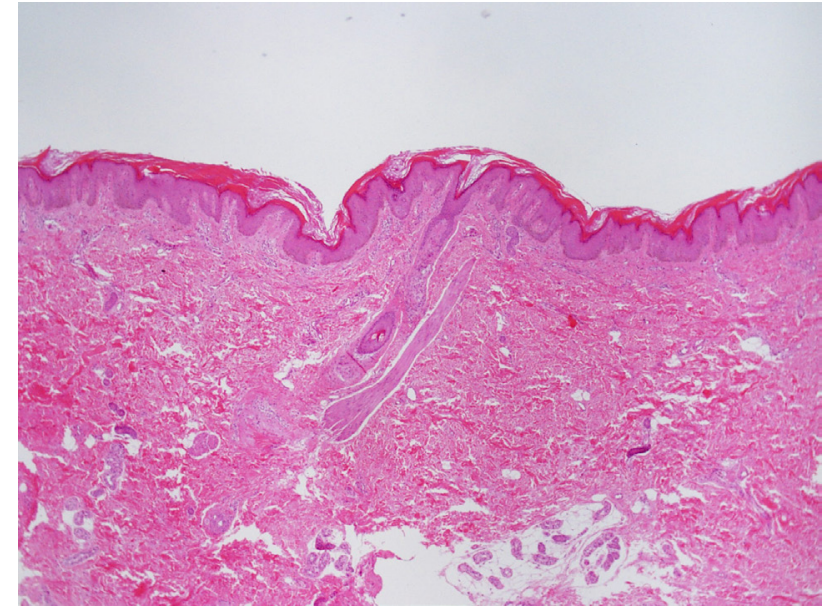

Figure 2 Histology shows hyperkeratosis, epidermal hyperplasia and follicular plugs $(\times 40)$.

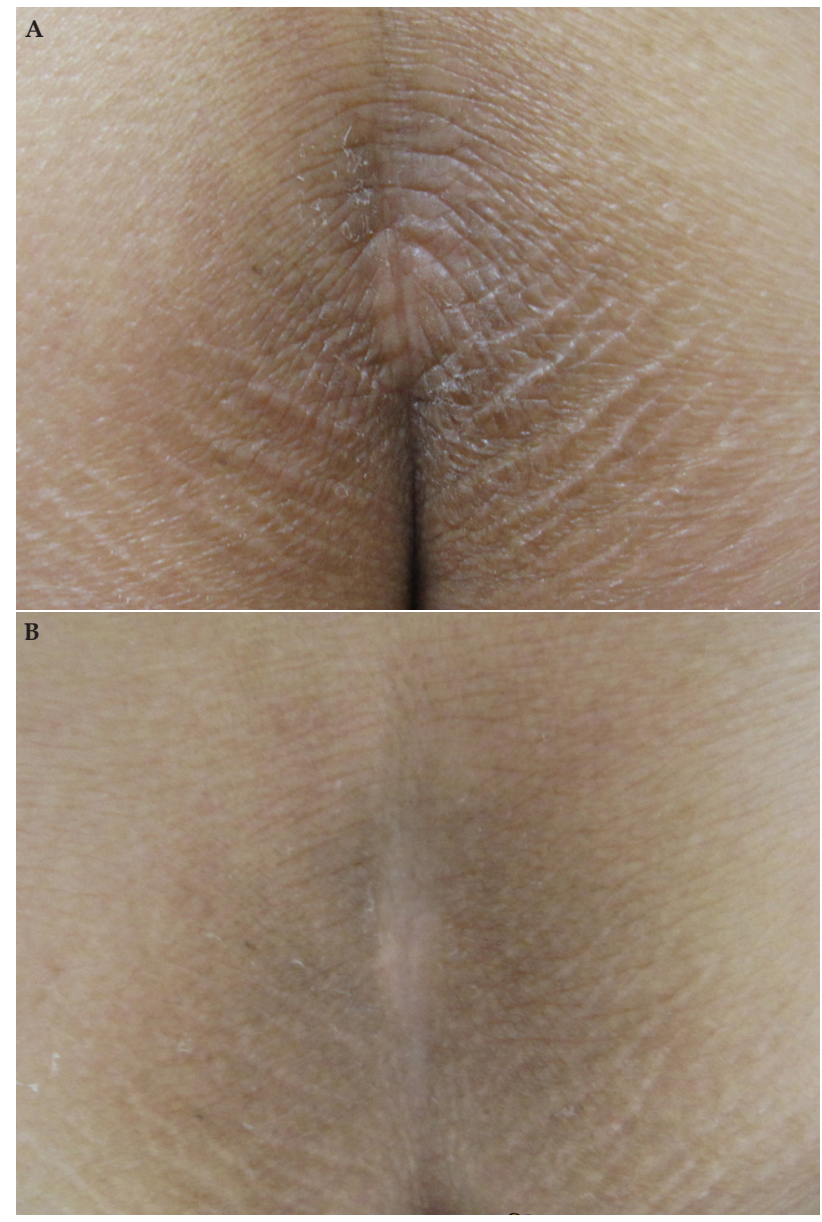

Figure 3 (A) A lesion before the treatment of activated vitamin D3 ointment. (B) An improved lesion after the treatment for four weeks.

lichen pilaris. Recently Ishizaki et al have recommended the third term because it is easy to understand ${ }^{[12]}$. These above papers were published in Japanese language.

There are some reports from Taiwan and Korea after 2000. Wang et al reported 10 cases of ano-sacral cutaneous amyloidosis proved by histological examinations including crystal violet, Congo red and Dylon stains ${ }^{[13]}$. Half of their cases developed the disease before the age of 60 years. In their cases amyloid deposits were not present around the hair follicles unlike Yangihara's observation. Eight cases 
of them involved other cutaneous amyloidosis. Liu et al described clinicopathologically 12 cases of senile gluteal dermatosis and 11 of ano-sacral cutaneous amyloidosis, and insisted on distinguishing them ${ }^{[3]}$. Liu et al ${ }^{[1]}$ reported 137 cases of senile gluteal dermatosis and Moon et $\mathrm{al}^{\left[{ }^{[4]}\right.}$ did 37 cases. Skin biopsies were performed in only 14 and eight cases respectively. They could not exclude cases of anosacral cutaneous amyloidosis.

It is impossible to distinguish these two diseases clinically. Most

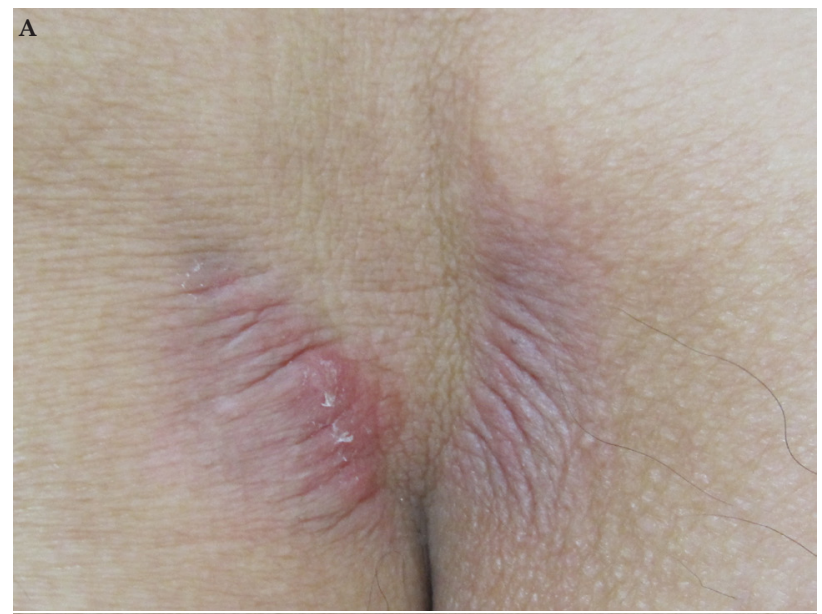

B

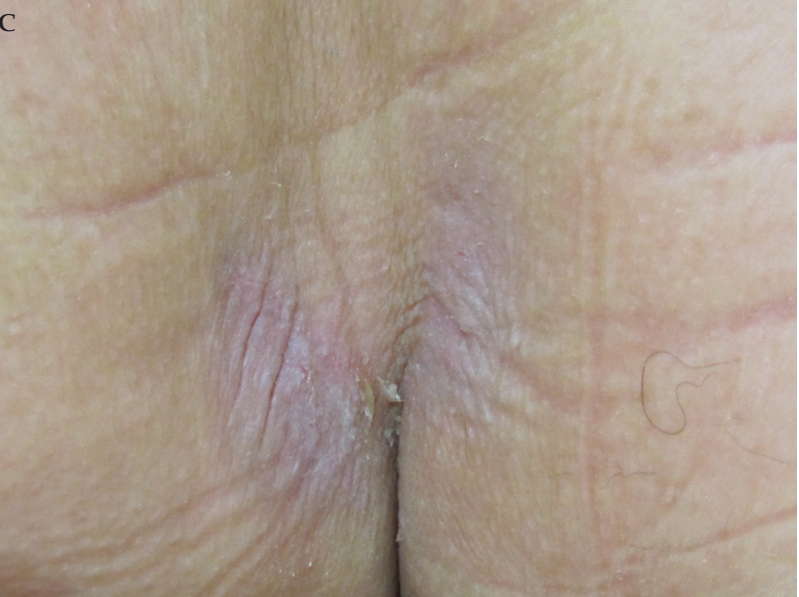

Figure 4 (A) A hypertrophic lesion before the treatment. (B) Applying wound covering materials. (C) An improved lesion after the treatment for a week. physicians will probably make diagnoses of senile gluteal dermatosis without histological examinations. The existence of amyloid deposits may not be important, however, it must be doubted. Some cases are accompanied by other cutaneous amyloidosis ${ }^{[9,13]}$. Topical steroids are thought to be not effective for senile gluteal dermatosis. Some lesions react to activated vitamin D3 ointment ${ }^{[14]}$ (Figure 3). Wound covering materials are effective for hypertrophic lesions, but are improper for long-term use (Figure 4). It is the most important not to sit on hard furniture or mats for long hours. Some cases are complicated with bedsores and fungal infection. This condition should be known widely among people taking care of the elderly. A simple term is preferable.

\section{ACKNOWLEDGMENTS}

I wish to thank Prof. Mariko Seishima (Gifu University) for her help.

\section{REFERENCES}

1. Liu HN, Wang WJ, Chen CC, Lee DD, Chang YT. Senile gluteal dermatosis: a clinical study of 137 cases. Int J Dermatol 2014; 53: 51-55. [PMID: 23675693]; [DOI: 10.1111/j.13654632.2012.05702.x]

2. Bos WH, Koning JDE. A senile gluteal dermatosis caused by friction. Eur J Dermatol 1992; 2: 157-159.

3. Liu HN, Wang WJ, Chen CC, Lee DD, Chang YT. Senile gluteal dermatosis -a clinicopathologic study of 12 cases and its distinction from anosacral amyloidosis. $J$ Eur Acad Dermatol Venereol 2012; 26: 258-260. [PMID: 22280513]; [DOI: 10.1111/j.14683083.2011.04045.x]

4. Moon SH, Kang BK, Jeong KH, Shin MK, Lee MH. Analysis of clinical features and lifestyle in Korean senile gluteal dermatosis patients. Int J Dermatol 2016; 55: 553-557. [PMID: 26234159]; [DOI: 10.1111/ijd.12838]

5. Yamamoto T, Mukai H. A kind of senile cutaneous change. Nishinihon J Dermatol 1979; 41: 798. (in Japanese)

6. Yanagihara M, Fukushima S, Izumi H, Mori S. Ano-sacral cutaneous amyloidosis. Jpn J Dermatol 1980; 90: 543-544. (in Japanese)

7. Yanagihara M. Ano-sacral cutaneous amyloidosis. Jpn J Dermatol 1981; 91: 463-471. (in Japanese)

8. Yamamoto T, Mukai H. Hyperkeratotic lichenified skin lesion of gluteal region in the elderly. Pract Dermatol 1985; 7: 1143-1146. (in Japanese)

9. Mukai H, Eto H, Yamamoto T. Ano-sacral cutaneous amyloidosis -Dylon positive material does not react with monoclonal antikeratin antibody EKH4—. Jpn J Dermatol 1981; 96: 1247-1251. (in Japanese)

10. Wakashin K. Hyperkeratotic lichenified skin lesion of gluteal region of the aged. Rinsho derma (Tokyo) 1998; 40: 833-836. (in Japanese)

11. Kojima L. Dermatosis on gluteal cleft-especially about gluteal skin roughness-. Rinsho derma (Tokyo) 2000; 42: 713-715. (in Japanese)

12. Ishizaki J, Machiya $\mathrm{C}$, Ishii Y. Gluteal skin roughness. Jpn J PU 2011; 13: 613-617. (in Japanese)

13. Wang WJ, Huang CY, Chang YT, Wong CK. Anosacral cutaneous amyloidosis: a study of 10 Chinese cases. Br J Dermatol 2000; 143: 1266-1269. PMID:11122031

14. Tabata K, Ueda A, Nagata M. Cases of ano-sacral cutaneous amyloidosis reacted to activated vitamin D3 ointment. Skin research 2007; 2: 228. (in Japanese)

Peer Reviewer: JAIME AGUSTI MARTINEZ 